\title{
Data Mining Techniques for the Life Sciences
}

\section{(Olivero Carugo and Frank Eisenhaber (eds.), in Series " Springer Protocols. Methods in Molecular Biology", Vol. 609, Humana Press, 2010, 407 p., \$110)}

DOI: $10.1134 / \mathrm{S} 0006297911040158$

The book highlights valuable data about sources of information and techniques used for "mining" new insights out of databases. The book consists of three parts with 22 chapters prepared by well-known experts from many countries.

The first part is devoted to databases and includes nine chapters. Chapters 1 and 2 highlight databases of nucleic acid sequence and structure, genomic databases, including sources from National Center for Biotechnology Information. Chapters 3-7 focus on databases for protein sequence, their structure, protein domain architectures, and thermodynamic and enzyme databases. Chapters 8 and 9 present databases about biomolecular pathway and protein-protein interactions and complexes.

The second part includes chapters 10-14 and highlights cluster analysis, algorithms, neural networks, and hidden Markov models in biology.
The third part focuses on databases of annotations and predictions. It consists of eight chapters (15-22) with relation to databases for biomolecular sequencebased function prediction, database for antibodies, sequence and structure analysis of noncoding RNAs, conformational disorders, and databases for prediction of secondary and quaternary protein structure. The last two chapters of this part (21 and 22) highlight databases for prediction of posttranslational modification of proteins from their amino acid sequence and crystallizability.

The book will be useful for students and researchers, such as biochemists, molecular biologists, and biotechnologists, who wish to get a condensed introduction to the world of biological databases and their applications related to various aspects of life science.

Doctor of Biological Sciences, G. Ya. Wiederschain 